\title{
PERANCANGAN PENGUKURAN KINERJA DI PT INDOCEMENT TUNGGAL PRAKARSA TBK. MENGGUNAKAN BALDRIGE EXCELLENCE FRAMEWORK 2015-2016
}

\author{
PERFORMANCE MEASUREMENT DESIGN IN PT INDOCEMENT TUNGGAL PRAKARSA TBK USING \\ BALDRIDGE EXCELLENCE FRAMEWORK OF 2015-2016
}

\author{
Almandri Nur Putra ${ }^{* 1}$, Arief Daryanto**), dan Sahara $\left.{ }^{* * *}\right)$ \\ *) PT Indocement Tunggal Prakarsa Tbk. \\ Jl. Mayor Oking Jayaatmaja, Citeureup Bogor 16810 \\ ${ }^{* *}$ Sekolah Bisnis, Institut Pertanian Bogor \\ Jl. Raya Pajajaran, Bogor 16151 \\ ${ }^{* * *}$ Departemen Ilmu Ekonomi, Fakultas Ekonomi dan Manajemen, Institut Pertanian Bogor \\ Jl. Agatis Kampus IPB Darmaga 16680
}

\begin{abstract}
Nowadays, Indonesia cement industry is facing a dissatisfactory condition. The national cement competition landscape has been changed. There are some new cement producers crowded out the industry. At the time, they can corrupt the market share of the existing players, including PT. Indocement Tunggal Prakarsa Tbk. as one of the biggest cement producers in Indonesia. To overcome this problem, one of the best solutions is to improve the performance, and it can be started with a favorable performance measurement system. This study used a well-known performance measurement tool of Baldrige Excellence Framework (BEF) of 2015-2016. This study aims to define the criteria of the Baldrige Excellence Framework of 2015-2016 of PT Indocement Tunggal Prakarsa, Tbk, to assess the performance based on the Baldrige Excellence Framework of 20152016, and to give strategic and exact suggestions on the company performance measurement, based on the strength and opportunity for improvement and BEF scoring result. Based on the result of this study, PT. Indocement Tunggal Prakarsa Tbk. scored 423.91 points indicating that the company is classified as Global Average class for its global performance criteria with the predicate of Early Improvement. This means that performance of the company has to be improved in any fields to strive an excellence company within all criteria.
\end{abstract}

Keywords: BEF, performance measurement, performance improvement, cement, PT Indocement

\begin{abstract}
Abstrak: Industri semen di Indonesia saat ini tengah menghadapi kondisi kurang menggembirakan. Lanskap persaingan semen nasional juga telah berubah. Banyak pendatang baru memasuki industri, dan dapat mengambil pangsa pasar para pemain lama, termasuk PT Indocement Tunggal Prakarsa Tbk. sebagai salah satu produsen semen terbesar di Indonesia. Untuk mengatasi hal itu, salah satu solusinya adalah dengan meningkatkan kinerja, dan peningkatan kinerja yang baik semestinya dimulai dengan penilaian kinerja yang memadai. Penelitian ini menggunakan alat pengukuran kinerja yang telah dipakai secara luas; Baldrige Excellence Framework (BEF) 2015-2016. Penelitian ini bertujuan untuk mendefinisikan kriteria-kriteria Baldrige Excellence Framework 2015-2016 di PT Indocement Tunggal Prakarsa, Tbk., melakukan penilaian kinerjanya berdasarkan Baldrige Excellence Framework 2015-2016, dan memberikan usulan strategis tentang pengukuran kinerja perusahaan, berdasarkan kekuatan (strength), peluang perbaikan (opportunity for improvement), dan hasil penilaian Baldrige Excellence Framework 2015-2016. Hasil survei PT Indocement Tunggal Prakarsa, Tbk. memperoleh skor total 423,91 poin. Hal itu menunjukkan PT Indocement Tunggal Prakarsa, Tbk. berada pada posisi atau klasifikasi kelas Global Average dengan predikat kriteria kinerja global perusahaan Early Improvement. Ini berarti kinerja Indocement masih harus melakukan banyak perbaikan menuju perusahaan yang excellence dari seluruh kriteria yang ada.
\end{abstract}

Kata kunci: BEF, pengukuran kinerja, peningkatan kinerja, semen, PT Indocement

\footnotetext{
${ }^{1}$ Corresponding author:

Email: putraandrie@gmail.com
} 


\section{PENDAHULUAN}

Industri semen di Indonesia tahun-tahun belakangan ini memasuki masa-masa sulit, pertumbuhan penjualan mengalami penurunan terus-menerus. Hampir seluruh produsen semen sejak 2012 meningkatkan kapasitas terpasangnya, ditambah dengan masuknya beberapa produsen semen baru. Hal tersebut berpotensi menggerus pangsa pasar pemain eksisting, jika tidak diantisipasi dengan strategi yang tepat.

Kondisi persaingan pasar yang ketat dan pasokan berlebih, menyebabkan laba bersih Indocement di tahun 2015 anjok 17,70\%, atau Rp4,40 triliun dari Rp5,30 triliun di tahun sebelumnya (Indocement, 2016). Meski penjualan semen nasional mengalami peningkatan sebesar $1.84 \%$ di tahun 2015 , yaitu dari 59,90 juta ton di tahun 2014 menjadi 61 juta ton di 2015, namun pertumbuhan penjualannya mengalami penurunan $45,45 \%$, dari $3,28 \%$ di 2014 menjadi $1,84 \%$ di tahun 2015 (Hartono dan Damagiri, 2015), seperti terlihat dalam Gambar 1.

Kondisi kompetisi seperti ini memaksa produsen semen eksisting termasuk Indocement untuk terus meningkatkan kinerjanya, agar tidak tersalip oleh para pendatang baru. Dalam upaya peningkatan kinerja, salah satu hal terpenting untuk diperhatikan adalah masalah pengukuran kinerja. Salah satu cara terbaik untuk memenangkan persaingan tersebut adalah dengan menjaga keunggulan kinerja. Menurut Summers (2005), sistem pengukuran kinerja yang efektif digunakan untuk mengerti, meluruskan, dan meningkatkan kinerja di semua tingkatan, pada seluruh bagian organisasi.

Sebagai salah satu upaya internal untuk meningkatkan penjualan dan menjaga kepemimpinan kualitas produk, diperlukan sistem pengukuran kinerja yang baik dan integral sebagai dasarnya. Untuk pengukuran kinerja, di Indocement sendiri, saat ini menggunakan sistem pengukuran kinerja bernama IPMS (Indocement Performance Management System). IPMS Indocement terdiri dari 6 parameter yang dinamakan 6 OSP (Optimal Success Parameter), yaitu kekuatan finansial (FS), kepuasan pelanggan (CS), produktivitas dan efisiensi (PE), tanggung jawab kepada masyarakat (PR), inovasi (IN), dan kualitas orang dan kerjasama kelompok (QT). Namun demikian, sistem IPMS menurut penulis masih menyisakan beberapa kelemahan atau kekurangan. Diantaranya adalah secara bangunan sistem, di antara KPM-KPM masing-masing bersifat parsial, tidak ada penghubung, katalis, atau mekanisme yang menghubungkan satu parameter dengan parameter lainnya.

Bertolak pada masalah-masalah tersebut, penulis berpendapat bahwa dirasa perlu untuk melakukan penyempurnaan sistem pengukuran kinerja di Indocement. Hal tersebut dapat dilakukan dengan cara, merancang sistem pengukuran kinerja yang lebih komprehensif dan teruji kehandalannya di dunia usaha, yaitu dengan menggunakan metode Baldrige Excellence Framework (BEF).

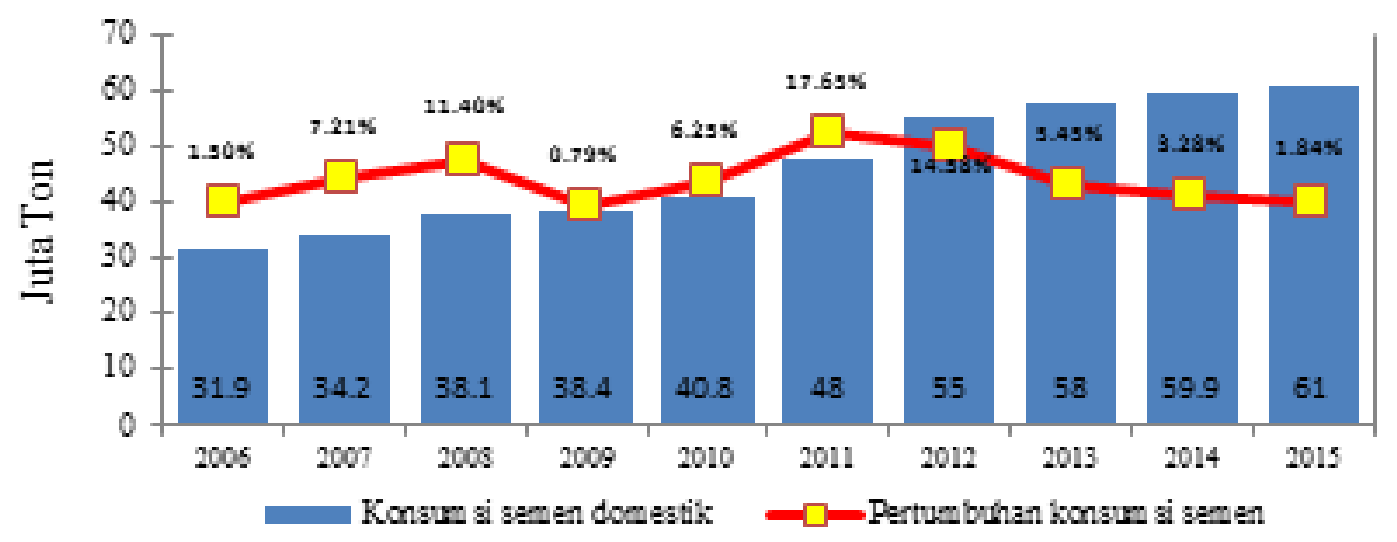

Gambar 1. Pertumbuhan konsumsi dan pasar semen di Indonesia (ASI, 2016) 
Rudjito et al.(2010), dalam penelitiannya yang berjudul "Keterkaitan Kategori Kepemimpinan dengan Enam Kategori Lainnya dalam Malcolm Baldrige Criteria for Performance Excellence (MBCfPE) pada Badan Usaha Milik Negara", menelaah hasil analisis diskriminan, dari kelima sub-sub kategori satu (kepemimpinan). Ia menemukan bahwa, yang paling banyak memiliki kontribusi unik paling tinggi atau yang paling membedakan antara kelompok perusahaan BUMN berpredikat good performance, dan di bawah good performance dalam hubungannya dengan pelaksanaan sub-sub kategori dua hingga sub-sub kategori tujuh MBCfPE adalah pelaksanaan Komunikasi dan Kinerja Perusahaan. Parast dan Jones, (2006), dalam tulisannya yang berjudul "A Relationship between Six Sigma and Malcolm Baldrige Quality Award", menuturkan bahwa model Baldrige tidak menyediakan tool atau teknik yang dapat digunakan untuk mencapai tingkat kinerja dan/atau target mutu yang diinginkan, meski salah satu persyaratan model baldrige adalah mencapai tingkat kinerja yang lebih baik.

Liang (2014), dalam tesisnya menyimpulkan bahwa, terdapat empat area kunci potensi perbaikan yang dapat dimasukkan ke Lean Six Sigma dan MBNQA; inovasi, teknologi, kontrol resiko, dan kegesitan. Keempat area kunci tersebut dapat membantu kedua kerangka kerja Lean Six Sigma dan MBNQA lebih efektif dalam meningkatkan daya saing kualitas dari 37 organisasi. Nugraha dan Arijanto (2014), dalam penelitiannya yang berjudul "Rancangan Sistem Perangkat Lunak untuk Internal Assessment Pengukuran Kinerja BEF Berbasis KPKU - BUMN" berhasil mengidentifikasi faktorfaktor Strengths dan Opportunities for Improvement bagi perusahaan, dengan hasil simpulan bahwa sistem perangkat lunak untuk internal assessment dapat menghasilkan perkiraan nilai akhir dari masing-masing kategori.

Gasperz dan Fontana (2011) menuliskan bahwa telah banyak organisasi-organisasi lokal maupun kelas dunia, memilih BEF sebagai kerangka kerja sistem manajemen untuk meningkatkan keunggulan kinerja organisasi. Dari kenyataan tersebut di atas, maka penulis berinisiatif untuk melakukan penelitian tentang perancangan metode pengukuran kinerja, yang dapat mengisi fungsi dan ruang kosong dari metode yang sekarang ini berlaku.
Tujuan penelitian ini adalah mendefinisikan kriteriakriteria BEF 2015-2016, melakukan penilaian kinerja berdasarkan BEF 2015-2016, dan memberikan usulan strategis tentang pengukuran kinerja perusahaan berdasarkan kekuatan (strength), peluang perbaikan (opportunity for improvement), dan hasil penilaian BEF 2015-2016 di PT Indocement Tunggal Prakarsa Tbk.

\section{METODE PENELITIAN}

Penelitian ini dilakukan di PT Indocement Tunggal Prakarsa Tbk. Beralamat di Jalan Mayor Oking Jayaatmaja Kecamatan Citeureup Kabupaten Bogor. Masa penelitian adalah dari Agustus sampai September 2016.

Dalam penelitian ini, jenis data yang digunakan adalah data primer dan data sekunder. Data primer diperoleh dengan melakukan pengamatan langsung di lapangan dan wawancara kepada pihak-pihak terkait dengan PT Indocement Tunggal Prakarsa, Tbk. Responden yang dipilih adalah karyawan yang lebih banyak mengetahui tentang perusahaan. Wawancara dilakukan kepada pihak manajemen PT Indocement Tunggal Prakarsa, Tbk. seperti junior management (superintendant, section Chief, dan planner) serta middle management (department head, manager, dan senior manager). Adapun unit-unit kerja yang dilibatkan dalam pengambilan sampel data kuisioner ini berasal dari unitunit kerja core business dan supporting. Responden yang dipilih adalah karyawan dengan beragam tingkatan yang lebih banyak mengetahui tentang perusahaan. Data sekunder merupakan data yang berkaitan dengan penelitian yang akan dilakukan. Data sekunder ini diperoleh dari pengkajian terhadap dokumen atau data laporan perusahaan, serta literatur yang mendukung topik penelitian ini seperti buku-buku yang memuat teori-teori, jurnal, skripsi, maupun penelusuran melalui internet.

Pendekatan penelitian yang digunakan dalam penelitian ini adalah metode deskriptif melalui studi kasus. Penggunaan studi kasus dilakukan untuk memperoleh gambaran, dan informasi lebih rinci mengenai suatu objek tertentu selama kurun waktu tertentu dengan cukup mendalam dan menyeluruh, termasuk lingkungan internal dan eksternal yang memengaruhinya (Nazir, 1999). Penentuan responden akan dilakukan secara nonprobability sampling, yaitu dengan menggunakan teknik purposive sampling (dipilih dengan sengaja), yang 
digunakan untuk menentukan responden yang menjadi individual in-depth interview. Teknik ini diharapkan dapat memberikan hasil yang diinginkan dan sample yang representatif. Pada metode ini, sampel responden diambil berdasar pada pertimbangan bahwa responden tersebut memiliki keahlian dan kompetensi pada bidang yang dikaji. Konsideran lainnya adalah; ketersediaan elemen dan kemudahan untuk mendapatkannya.

Hasil penelitian ini disajikan dengan mengunakan metode deskriptif, yaitu dengan mengumpulkan data dari perusahaan kemudian diolah dengan menggunakan analisis pengukuran BEF 2015-2016. Adapun langkahlangkah mengolah data penelitiannya adalah sebagai berikut:

1. Mengidentifikasi dan menguraikan fakta perusahaan, nilai kekuatan (strength) dan Opportunity for Improvement (OfI) untuk setiap kriteria menggunakan kriteria BEF 2015-2016, lalu proses dilanjutkan dengan mengarahkan kriteria pada A-D-L-I (Approach, Deployment, Learning, dan Integration) (Prawira et al. 2013).. Pada item kriteria hasil diarahkan pada metode L-T-C-I (Level, Trend, Comparison, dan Integration).

2. Melakukan identifikasi perolehan bobot penilaian di setiap item kriteria.

3. Menentukan skor total pengukuran kinerja menggunakan formula:

a. Skor item kriteria $=$ Bobot item kriteria $\mathrm{x}$ Poin item kriteria.

b. Skor kriteria $=\sum$ skor item kriteria.

c. Skor total (hasil scoring) $=\sum$ skor kriteria.

4. Menentukan klasifikasi kelas kinerja perusahaan berdasarkan hasil scoring.

5. Tahap terakhir menyusun rekomendasi atau saran pada perusahaan mengenai hal-hal yang perlu diperbaiki, ditingkatkan, dan dilengkapi kinerjanya.

Setiap organisasi yang baik pasti memiliki visi dan misi yang ditetapkan bersama. Setelah visi dan misi dikaji, informasi tambahan seperti profil perusahaan dan sebagainya dapat digunakan untuk merespon persyaratan yang ada pada tujuh BEF, yang meliputi leadership, strategy, customer, measurement, analysis, and knowledgemanagement, workforce, operations, dan result. Selanjutnya, kategori tersebut menurut Sadikin (2010), dikaji melalui kriteria penilaian baldrige. Ada dua dimensi kriteria penilaian tersebut, yaitu pertama dimensi proses, mengacu pada metode perusahaan atau organisasi. Dimensi kedua ialah hasil, mengacu pada results perusahaan dalam mencapai persyaratan item kategori. Evaluasi proses dan evaluasi hasil tersebut diukur berdasarkan panduan penilaian yang ada pada metode BEF sehingga diperoleh skor untuk menganalisis kinerja perusahaan tersebut. Di dalam proses penilaian, antara penilaian proses dan hasil saling terkait. Apabila proses penilaian telah dilakukan, maka hasil penilaian yang diperoleh selanjutnya digunakan untuk mengetahui tingkat atau posisi kinerja perusahaan tersebut saat ini. Setelah diketahui kinerja dari masing-masing kriteria maka langkah terakhir yaitu membuat rekomendasi atau menunjukan hasil penelitian mengenai apa yang perlu ditingkatkan atau diperbaiki berdasarkan pada hasil penilaian dan pengamatan. Implementasi saran dan rekomendasi yang diberikan bukanlah merupakan sebuah proses akhir. Perusahaan harus tetap melakukan continuous improvement agar dapat terus meningkatkan kapasitas dan kapabilitas dirinya agar kinerja ekselennya dapat terjaga sekaligus memenangkan persaingan

\section{HASIL}

\section{Nilai dan Posisi Kinerja Perusahaan}

Hasil tabel skor PT Indocement Tunggal Prakarsa, Tbk (Tabel 1) memperoleh skor total 423,91 poin dengan rincian, kategori proses mendapatkan skor 253,41 poin dan kategori hasil memiliki skor 170,50 poin. Hal itu menunjukan PT Indocement Tunggal Prakarsa, Tbk. berada pada posisi atau klasifikasi kelas Global Averange pada range 376-475 dengan kriteria kinerja global perusahaan atau predikat Early Improvement. Seperti terlihat pada Tabel 2, merupakan posisi kelas kinerja Indocement.

Untuk lebih mempertajam analisis mengenai hasil penilaian responden dengan bobot nilai standar BEF 2015-2016, dapat dibantu dengan analisis gap. Agar proporsional dengan penilaian standar BEF 2015-2016, data penilaian kuesioner dijadikan sebagai pengurang dari nilai standar BEF 2015-2016, lalu dikonversi menjadi persentase, karena setiap item kriteria memiliki bobot nilai berbeda-beda. Penjelasan analisis gap tersebut dapat dilihat pada Tabel 3, dan pemetaan sebaran gap pada tiap-tiap kriteria dapat dilihat pada Gambar 2. 
Tabel 1. Skor total masing-masing kriteria BEF 2015-2016

\begin{tabular}{|c|c|}
\hline Kriteria & Poin \\
\hline Leadership & 56,88 \\
\hline Strategy & 35,44 \\
\hline Customers & 42,97 \\
\hline Measurement, analysis, and knowledge management & 39,94 \\
\hline Workforce & 39,09 \\
\hline Operations & 39,09 \\
\hline Results & 170,50 \\
\hline Nilai total & 423,91 \\
\hline
\end{tabular}

Tabel 2. Posisi kinerja Indocement berdasarkan BEF 2015-2016

\begin{tabular}{lcll}
\hline Klasifikasi kelas perusahaan & Skor & Kinerja global perusahaan & Posisi perusahaan \\
\hline Poor & $0-275$ & Early development & Indocement \\
Global Average & $276-375$ & Early result & Early improvement \\
& $376-475$ & Good performance & Emerging industry leader \\
Global & $476-575$ & Industry leader \\
Image Excellent & $576-675$ & Benchmark leader \\
& $676-775$ & World class leader \\
\hline
\end{tabular}

Tabel 3. Analisis gap

\begin{tabular}{lccccc}
\hline \multicolumn{1}{c}{ Kriteria } & Values & Point & $\% \mathrm{P}$ & $\Delta$ & $\% \Delta$ \\
\hline Leadership & 120 & 56,88 & $47,40 \%$ & 63,13 & $52,60 \%$ \\
Strategy & 85 & 35,44 & $41,69 \%$ & 49,56 & $58,31 \%$ \\
Customers & 85 & 42,97 & $50,55 \%$ & 42,03 & $49,45 \%$ \\
Measurement, analysis, and knowledge management & 90 & 39,94 & $44,38 \%$ & 50,06 & $55,63 \%$ \\
Workforce & 85 & 39,09 & $45,99 \%$ & 45,91 & $54,01 \%$ \\
Operations & 85 & 39,09 & $45,99 \%$ & 45,91 & $54,01 \%$ \\
Results & 450 & 170,50 & $37,89 \%$ & 279,50 & $62,11 \%$ \\
Nilai Total & 1000 & 423,91 & $44,84 \%$ & 576,09 & $55,16 \%$ \\
\hline
\end{tabular}

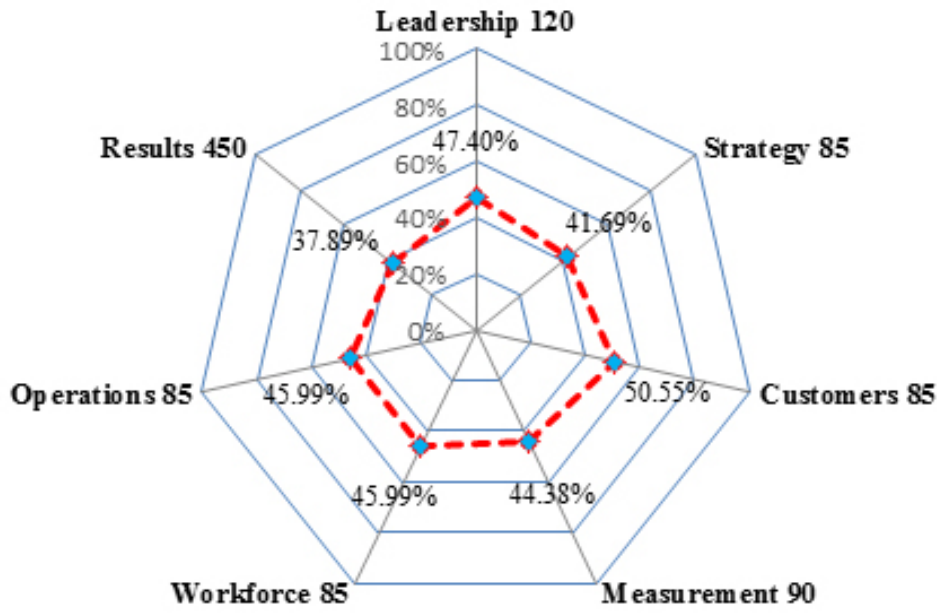

Gambar 2. Radar perolehan nilai BEF 2015-2016 Indocement 
Hasil analisis gap untuk masing-masing kriteria menunjukan bahwa, kriteria strategi pada kategori proses memiliki nilai gaps tertinggi, yaitu 49,56 poin atau mencapai $58,31 \%$. Berdasarkan fakta yang diperoleh perusahaan telah memiliki pendekatan (approach) yang sistematis dan efektif dalam memimpin perusahaan, seperti penerapan visi, misi dan tata nilai perusahaan, responsif terhadap persyaratan mendasar kategori BEF 2015-2016. Pendekatan tersebut disosialisasikan keseluruhan karyawan dan dijalankan sesuai dengan unit kerja yang ada. Untuk kategori hasil memiliki gaps yang tinggi, yaitu 279,50 poin atau $62,11 \%$ dari nilai maximum. Berdasarkan evaluasi hasil secara keseluruhan perusahaan tidak melaporkan data benchmark dan evaluasi dengan trend sedikit dilaporkan. Hal ini menunjukan bahwa Indocement belum maksimal dalam orientasi hasil.

\section{Strength and Opportunity for Improvement Setiap Kriteria}

Untuk kriteria proses, perusahaan memiliki strength pada aspek approach (pendekatan) dan deployment (penerapan) yang digunakan dalam menangani proses. Program peningkatan K3 di perusahaan, penerapan visi, misi, dan nilai-nilai perusahaan seperti Indocement Way, kemauan mendengar suara pelanggan, dan harmonisasi hubungan dengan pekerja menjadi nilai kekuatan/ strength bagi Indocement. Adapun Opportunity for Improvement (OfI) untuk kategori hasil, adalah masih perlunya pemerataan pengetahuan tentang programprogram perusahaan, peningkatan upaya mendapatkan pelanggan baru, dan pelibatan karyawan dalam melakukan job evaluation merupakan peluang-peluang perbaikan organisasi ke depan.

Hasil penelitian strength and opportunity for improvement ini sejalan dengan penelitian Nugraha dan Arijanto (2014), dalam penelitiannya yang berjudul "Rancangan Sistem Perangkat Lunak untuk Internal Assessment Pengukuran Kinerja BEF Berbasis KPKU - BUMN", yang berhasil mengidentifikasi faktorfaktor strengths dan opportunities for improvement bagi kemajuan perusahaan.

\section{Usulan Strategis untuk Pengukuran Kinerja di PT Indocement Tunggal Prakarsa Tbk.}

Sebagaimana penulis nyatakan dalam ruang lingkup penelitian, bahwa perancangan pengukuran kinerja dibatasi kepada penilaian bobot kriteria BEF 2015-
2016 berdasarkan hasil penelitian, untuk kemudian dicari kelebihan yang ada dari hasil penelitian, guna melengkapi apa yang dirasa kurang dalam sistem penilaian kinerja yang digunakan PT Indocement Tunggal Prakarsa Tbk. saat ini (IPMS).

Dari hasil pengukuran di atas, terlihat bahwa sistem pengukuran BEF 2015-2016 dapat diterapkan di PT Indocement Tunggal Prakarsa Tbk. Kriteria hasil-hasil (results) menelaah kinerja organisasi dan peningkatan perbaikan di seluruh area penting hasil produk dan proses, hasil fokus pada pelanggan, fokus tenaga kerja, hasil kepemimpinan dan tata-kelola, dan hasil keuangan dan pasar.

Pendekatan sistem penilaian hasil-hasil (results) memperlihatkan posisi tingkat keberhasilan kinerja dan bagaimana tren data yang dilaporkan, ada informasi pembanding (comparison), dan integrasi memperlihatkan bagaimana pendekatan sudah sejalan dengan kebutuhan organisasi. Pengukuran, informasi, dan perbaikan sistem sifatnya saling melengkapi diantara proses-proses dan unit kerja, dan perencanaan, proses, hasil, analisis, pembelajaran, dan tindakan diharmonisasi sesuai proses-proses dan unit kerja untuk mendukung tujuan besar organisasi. Di kriteria hasil-hasil (results) inilah proses integrasi kriteriakriteria BEF 2015-2016 dilihat tingkatannya, arah atau trennya, perbandingannya, dan bagaimana integrasinya, disinergikan untuk mencapai tujuan organisasi.

\section{Implikasi Manajerial}

Hasil strengh dan opportunity for Improvement dari masing-masing kriteria, dapat dibuat implikasi manajerial untuk Indocement yang dapat dijadikan rekomendasi sebagai bahan pertimbangan dan masukan guna meningkatkan kinerja perusahaan. Implikasi manajerial tersebut diantaranya adalah sebagai berikut:

1. Kepemimpinan

Untuk lebih ditingkatkannya integrasi pada area kepemimpinan perusahaan melalui aktivitas saling melengkapi diantara proses dan unit kerja, seperti membangun keteladanan top level management yang mengakar, dan mengembangkan team work solid dengan cara membangun situasi kerja kondusif, dan senantiasa menerapkan GCG dengan baik.

2. Strategi

Strategi yang diterapkan Indocement saat ini merupakan hasil evolusi, dan sebuah penegasan 
akan keinginan perusahaan untuk terus menjadi pemimpin dalam industri semen nasional. Untuk lebih mendekatkan dan menyelaraskan antara strategi dan pemenuhan kebutuhan perusahaan.

3. Pelanggan

Demi menjaga pelanggan dan pangsa pasar, hal yang sebaiknya dilakukan Indocement adalah mengintegrasikan antara complaint management system atau customer management dengan supply chain management, agar dapat saling mendukung dalam meningkatkan kepuasan pelanggan, dengan meminta umpan balik (feed back) dari pelanggan.

4. Pengukuran, Analisis, dan Manajemen Pengetahuan

Mengevaluasi sistem kinerja IPMS yang saat ini digunakan, dan mengintegrasikan dengan sistem penilaian karyawan/konduite individual, menganalisis bobot pekerjaan (jobload), tenaga kerja dinamis di antara unit kerja (fluid workfoce system), untuk membagi pengetahuan tentang pekerjaan (sharing knowledge), mendirikan innovation center atau knowledge center, melengkapi training center dan safety learning center yang sudah ada.

5. Tenaga kerja

Untuk meningkatkan kinerja dan engagement karyawan, Indocement harus melakukan pelatihan dan mendorong pendekatan sistematis tentang bagaimana menjembatani perbedaan generasi (generation gap) antara pekerja senior dan junior, mendorong implementasi keselamatan dan kesehatan kerja (K3) karyawan berbasis perusahaan kelas dunia, dengan mengefektifkan pelaksanaan pedoman keselamatan perusahaan (live saving rules).

6. Operasi/Pekerjaan

Agar terwujud visi operational excellence, perusahaan harus mendorong proyek-proyek inovasi dan penemuan metode kerja baru agar dapat mendukung kebijakan efesiensi dan meningkatkan kualitas kerja, melakukan studi perbandingan atau benchmarking di grup Heidelberg Cement dan pihak lain, untuk dapat diterapkan di Indocement.

7. Hasil-hasil

Pencapaian kinerja kriteria yang paling rendah ialah kriteria strategi, dari sini dapat diusulkan untuk menyediakan parameter yang lebih jelas akan pencapaian strategi yang diterapkan, diperluas pemahaman strateginya dan disesuaikan dengan visi, misi, dan nilai-nilai perusahaan. Tren dan proses pembelajaran di kriteria operations dan workforce dapat ditingkatkan sesuai dengan kesenjangan yang ada antara standar nilai perusahaan kelas global dan kondisi eksisting perusahaan saat ini. Proses integrasi hasil-hasil dapat dilakukan secara bertahap dan menyesuaikan dengan visi dan misi perusahaan, agar langkah perbaikan dapat dilakukan lebih luas lagi dampak positifnya.

\section{KESIMPULAN DAN SARAN}

\section{Kesimpulan}

Pengukuran kinerja di PT Indocement Tunggal Prakarsa Tbk. saat ini menggunakan sistem IPMS (Indocement Performance Measurement System) yang terdiri dari 6 parameter yang dinamakan 6 OSP (Optimal Success Parameter), yaitu kekuatan finansial (Financial Strength/FS), kepuasan pelanggan (Customer Satisfaction/CS), produktivitas dan efisiensi (Productivity \& Efficiency/PE), tanggung jawab kepada masyarakat (Public Responsibilityl PR), inovasi (Innovation/IN), dan kualitas orang dan kerjasama kelompok (Quality of People \& Teamwork/ QT). Kondisi kinerja perusahaan yang dinilai melalui kriteria Baldrige atau BEF 2015-2016, menunjukkan bahwa perlu meningkatkan kualitas evaluasi dan sistematika pembelajaran (learning), akan lebih baik lagi jika kriteria BEF 2015-2016 dan Key Performance Indicator (KPI) IPMS diintegrasikan (integration).

Hasil penelitian menunjukkan bahwa kriteria BEF 2015-2016 yang dinilai responden paling tinggi adalah kriteria pelanggan (customer) dengan poin 42,97 atau mencapai $50,55 \%$ dari nilai standar BEF 85 poin. Di sisi lain kriteria paling lemah ada pada kriteria strategi, dengan poin 35,44 atau setara dengan 41,69\% dari nilai standar BEF 85 poin. Namun, di sisi lain keseluruhan pendekatan (approach) dan pengembangan (deployment) perusahaan cukup baik, sistematis, dan diterapkan pada unit kerja yang sesuai. Pada bagian penilaian kinerja berorientasi hasil, secara keseluruhan menunjukkan tren dan comparison.

Hasil evaluasi kinerja PT Indocement Tunggal Prakarsa, Tbk. berdasarkan metode BEF 2015-2016 diperoleh nilai skor total perusahaan sebesar 422,34 poin, maka posisi kelas kinerja perusahaan berada pada kategori early improvement di kelas perusahaan rata-rata dunia (global average). Ini berarti kinerja Indocement masih 
harus melakukan banyak perbaikan dan peningkatan kinerja menuju perusahaan yang excellence dari seluruh kriteria yang ada.

\section{Saran}

Dari hasil penelitian ini penulis mengajukan beberapa saran, pertama perusahaan dapat meningkatkan kinerjanya dengan memaksimalkan strength yang dimilikinya, dan melakukan perbaikan-perbaikan berdasarkan item-item dalam Opportunity for Improvement (OfI), lalu kedua, sebaiknya hasil penelitian ini tidak berhenti digunakan sebagai penduan untuk menentukan penilaian perusahaan saja, namun dapat dikembangkan menjadi panduan untuk memperbaiki kinerja perusahaan, menjadi jauh lebih baik menggunakan kerangka BEF 2015-2016. Selanjutnya, untuk mencapai hasil penilaian yang lebih baik dan komprehensif, sebaiknya penelitian dilakukan dalam skala pelibatan karyawan yang lebih luas dan merata di seluruh jenjang/jabatan di perusahaan.

\section{DAFTAR PUSTAKA}

Gaspersz V, Fontana A. 2011. Malcolm Baldrige Criteria for Performance Excellence-Contoh Aplikasi Pemenang Malcolm Baldrige Award. Bogor: Vinchristo Publication.
Hartono AF, Damagiri S. 2015. Fighting on uphill battle. Danareksa Research Report on Cement Sector/Initiating Coverage December 2015.

Liang PC. 2014. A review of lean six sigma and malcolm baldrige national quality award and aproposal for the future [tesis]. Singapura: National University of Singapore.

Nazir M. 1999. Metode Penelitian. Cetakan Ketiga. Jakarta: Ghalia Indonesia.

Nugraha C, Arijanto. S. 2014. Rancangan sistem perangkat lunak untuk internal assessment pengukuran kinerja BEF berbasis KPKUBUMN. Jurnal Itenas Rekayasa (Jurnal Teknologi Institut Teknologi Nasional) 18(1):3241.

Parast MM, Jones EC. 2006. A Relationship between Six Sigma and Malcolm Baldrige Quality Award, Dalam: Seminar IIE Annual Conference. 2006 Mei 22; Orlando, Amerika Serikat. Orlando: IIE

Prawira AS, Arijanto S, Nugraha C. 2013. Sistem perangkat lunak untuk internal assessment malcolm baldrige criteria for performance excellence (kriteria 1-kepemimpinan). Jurnal Online Institut Teknologi Nasional 1(2): 139149.

Rudjito, Daryanto A, Mangkuprawira S, Achsani N. 2011. Keterkaitan kategori kepemimpinan dengan enam kategori lainnya dalam Malcolm Baldrige Criteria For Performance Excellence (MBCFPE) pada badan usaha milik negara. Jurnal Manajemen \& Agribisnis 7(2): 97-114. 